\title{
Increased circulating paternal antigen-specific IFN- $\gamma$ - and IL-4-secreting cells during pregnancy in allergic and non-allergic women
}

\author{
Marie Persson, Christina Ekerfelt, Jan Ernerudh, Leif Matthiesen, Maria Jenmalm, Yvonne
} Jonsson, Martina Sandberg and Göran Berg

\section{Linköping University Post Print}

\section{Tweet}

N.B.: When citing this work, cite the original article.

Original Publication:

Marie Persson, Christina Ekerfelt, Jan Ernerudh, Leif Matthiesen, Maria Jenmalm, Yvonne Jonsson, Martina Sandberg and Göran Berg, Increased circulating paternal antigen-specific IFN- $\gamma$ - and IL-4-secreting cells during pregnancy in allergic and non-allergic women, 2008, Journal of Reproductive Immunology, (79), 1, 70-78.

http://dx.doi.org/10.1016/j.jri.2008.07.001

Copyright: Elsevier http://www.elsevier.com/ 


\title{
Increased circulating paternal antigen- specific IFN- $\gamma$ and IL-4 secreting cells during pregnancy in allergic and non-allergic women
}

\author{
Marie Persson $^{\mathrm{a}}$, Christina Ekerfelt ${ }^{\mathrm{a}}$, Jan Ernerudh ${ }^{\mathrm{a}}$, Leif \\ Matthiesen $^{\mathrm{b}}$, Maria Jenmalm ${ }^{\mathrm{c}}$, Yvonne Jonsson ${ }^{\mathrm{a}}$, Martina Sandberg ${ }^{\mathrm{c}}$ \\ and Göran Berg ${ }^{\text {b }}$ \\ ${ }^{a}$ Unit for Autoimmunity and Immune Regulation, Division of Clinical \\ Immunology, ${ }^{\mathrm{b}}$ Division of Obstetrics and Gynecology, ${ }^{\mathrm{C}}$ Division of Pediatrics. ${ }^{\mathrm{a}, \mathrm{b}}$, \\ ${ }^{c}$ Department of Clinical and Experimental Medicine, Faculty of Health Sciences, \\ Linköping University, S-581 85 Linköping, Sweden.
}

Corresponding author: Marie Persson, AIR, Division of Clinical Immunology, Faculty of Health Sciences, University Hospital, S-581 85 Linköping. Telephone: +4613227357 E-mail: marie.persson@imk.liu.se 


\section{ABSTRACT}

Introduction: Allergic women have been reported to give birth to more children than nonallergic women, speculatively explained by the former's predisposition for Th2 polarization, possibly favoring pregnancy. Aim: The aim of this study was to test the hypothesis that allergy is associated with more Th2-deviated responses to paternal antigens throughout pregnancy. Methods: Blood samples were collected on six occasions during pregnancy and two occasions post partum. Of the 86 women initially included, 54 women had a normal pregnancy and completed the sampling procedures. Eleven women fulfilled the strict criteria for allergy (allergic symptoms and circulating IgE antibodies to inhalant allergens) and 23 were strictly non-allergic (non-sensitized without symptoms). The numbers of blood mononuclear cells secreting IFN- $\gamma$ and IL-4, spontaneously and in response to paternal allo-antigens, were compared between the groups. Results: The numbers of spontaneously as well as paternal antigen induced IFN- $\gamma$ and IL-4-secreting cells were similar in allergic and non-allergic pregnant women on all occasions. A similar increase in the numbers of both IFN- $\gamma$ and IL-4-secreting cells were found in allergic and non-allergic women during pregnancy, both regarding spontaneous and paternal antigen induced secretion. Conclusions: The present study does not support the hypothesis of a more pronounced Th2-deviation to paternal antigens in allergic pregnant women compared with non-allergic pregnant women, as measured by number of cytokine secreting cells. The observed increase of both IFN- $\gamma$ and IL-4 secreting cells during normal pregnancy may be interpreted as a Th2situation, since the effects of IL-4 predominate over the effects of IFN- $\gamma$. 


\section{INTRODUCTION}

Pregnancy may be considered as an immunological paradox, since the fetus expresses paternal MHC antigens and therefore can be regarded as a semi-allograft. A substantial number of studies indicate a redirection of the immune responses towards a less aggressive type during pregnancy (Wegmann et al., 1993; Raghupathy et al., 2000). A T helper type 1 (Th1) to T helper type 2 (Th2) shift has been reported to characterize the third trimester, with a decreased production of the Th1 cytokine IFN- $\gamma$, and an increased production of the Th2 cytokines IL-4 and IL-6 (Marzi et al., 1996; Saito et al., 1999; Aris et al., 2008). We have previously shown that pregnant women have a higher number of both IFN- $\gamma$ and IL-4 expressing mononuclear cells in blood than non-pregnant women (Matthiesen et al., 1998; Matthiesen et al., 2003). Furthermore, pregnant women showed increased numbers of IL-4 secreting cells in blood in response to paternal allo-antigens, indicating a Th2-response directed against the fetus during pregnancy (Ekerfelt et al., 1997).

Significantly higher serum levels of the Th1 cytokine IFN- $\gamma$ have been detected in women with unexplained recurrent spontaneous abortions (Raghupathy et al., 1999). Several similar studies indicate increased Th1-like and decreased Th2-like responses among women with pregnancy losses, whereas women with successful pregnancies tend to have an increased Th2like response (Raghupathy et al., 2000; Makhseed et al., 2000; Makhseed et al., 2001; Kwak-Kim et al., 2003). An immune deviation towards Th2 has also been found locally at the maternal-fetal interface in healthy pregnant women (Lin et al., 1993), while a decreased local production of Th2 cytokines has been demonstrated in women with unexplained recurrent spontaneous abortions (Piccinni et al., 1998). 
Altogether, these studies suggest that a deviation towards Th2 is beneficial for pregnancy and that Th1 responses may be detrimental. Atopic disease is characterized by an individual predisposition to develop $\operatorname{IgE}$ mediated allergies against environmental allergens (Ishizaka and Ishizaka, 1971) and a Th2-polarized immunity (Del Prete et al., 1993). Atopic patients have an enhanced ability to produce IL-4, not only in response to allergens, but also to other antigens (Parronchi et al., 1992), and in line with this, atopic disease is associated with low IFN- $\gamma$ secretion (Parronchi et al., 1991; Shimojo et al., 1996)). However, we have previously found an IL-4 response to birch only in birch sensitized patients but not in cat sensitized patients, and vice versa (Jenmalm et al., 2001).

The Th2 deviation in atopic disease may be beneficial for a successful pregnancy outcome. The findings of Nilsson and colleagues that mothers with allergic disease (i. e. hay fever, allergic rhinitis, asthma or dermatitis) had more children than non-allergic mothers (Nilsson et al., 1997), support this hypothesis, as well as the findings of Savilahti and colleagues that mothers of very low birth weight infants had less allergic rhinitis than mothers of full-term infants (Savilahti et al., 2004). Newborn infants of mothers with allergic rhinitis have also been found to have higher birth weight and longer gestational age than newborn infants of non-allergic mothers (Somoskovi et al., 2007). However, an inverse relationship between maternal atopy and the number of offspring has also been reported (Sunyer et al., 2001; Karmaus and Eneli, 2003; Sunyer et al., 2005).

The aim of this study was to test the hypothesis that allergic women have a more pronounced Th2 deviation throughout pregnancy than non-allergic women by comparing the secretion of IFN- $\gamma$ and IL-4 from peripheral blood mononuclear cells (PBMC) of pregnant allergic and non-allergic women, spontaneously and in response to paternal allo-antigens. 


\section{MATERIALS AND METHODS}

\subsection{Subjects}

The eighty-six pregnant women included in the study (Figure 1) were all attending the Antenatal Clinic at the University Hospital in Linköping. All women accepted to participate in the study after informed consent. The study was approved by the Human Research Ethics Committee at the Faculty of Health Sciences in Linköping.

The allergic status of the women was established by a typical clinical history, $e g$ allergic rhinoconjunctivitis, allergic asthma or flexural itchy eczema. An experienced allergy research nurse used a structured questionnaire to interview the women. To further strengthen the diagnosis of atopy, allergy screening was performed using the Phadiatop system (Pharmacia, Uppsala, Sweden), which detects circulating IgE antibodies against common inhalant allergens, e. g. birch, mugwort, timothy, cat, dog, horse, house-dust mite, Cladosporium and Alternaria. Women who had both typical clinical symptoms and a positive Phadiatop test were considered as allergic. Women with no clinical symptoms and a negative Phadiatop test were considered as non-allergic. Among the women who had a pregnancy considered as normal $(n=54$, defined as a pregnancy without medical complications), gave birth to a healthy child and completed the study, 34 women fulfilled either of the criteria for diagnosis of allergy or absence of allergy (figure 1). Eleven pregnant women (age 26.2-39.7 years; median 30.4 years) were diagnosed as allergic and 23 pregnant women (age 26.9-37.2 years; median 30.8 years) as non-allergic.

\subsection{Collection of samples}

Blood samples were collected on six occasions during pregnancy (gestational weeks 10-12, 15-16, 25, 35, 39 and 41), 8-12 weeks after delivery (post partum, pp) and 12 months pp. All 
blood samples were drawn between 8 a.m. and 2 p.m. and processed within four hours. Heparinized peripheral blood was separated on Lymphoprep (Nycomed Pharma AB, Oslo, Norway) according to Bøyum (Boyum, 1968) and washed twice with Hank's balanced salt solution (HBSS; Life Technologies, Paisley, Scotland), pH 7.2. Peripheral blood mononuclear cells (PBMC) were resuspended in tissue culture medium (TCM) consisting of Iscove's modification of Dulbecco's medium (IMDM; Gibco, BRL, Paisley, Scotland) supplemented with (given as final concentrations in the medium): L-glutamine (Flow Lab, Irvine, Scotland) 292 mg/L; sodium bicarbonate (Sigma Aldrich, Stockholm, Sweden) $3.024 \mathrm{~g} / \mathrm{L}$; penicillin $50 \mathrm{U} / \mathrm{mL}$; streptomycin $50 \mu \mathrm{g} / \mathrm{mL}$ (PEST; Flow Laboratories, Irvine, UK); 100 x non-essential amino acids (Invitrogen, Stockholm, Sweden) $10 \mathrm{~mL} / \mathrm{L}$; and 5\% heat-inactivated fetal calf serum (FCS; Flow Laboratories). PBMC were frozen in TCM containing 10\% dimethyl sulphoxid (DMSO; Sigma Chemical Co., St Louise, MO, USA) and 50\% FCS at a cell density of 5x10 $\mathrm{PBMC} / \mathrm{mL}$ and at a rate of $-1{ }^{\circ} \mathrm{C} / \mathrm{min}$ to $-70^{\circ} \mathrm{C}$, after which the cells were stored in liquid nitrogen. Corresponding paternal PBMC were collected on one occasion, and the same procedure for separation and freezing was used as for the PBMC from the pregnant women.

\subsection{Thawing of maternal lymphocytes (responder cells) and stimulator cells}

Frozen PBMC from all samples taken in each individual during pregnancy and after delivery were thawed on the same occasion in a $37^{\circ} \mathrm{C}$ water bath. The cell suspensions were transferred to polypropylene tubes, to which pre-warmed TCM containing $10 \%$ FCS was added dropwise. The cells were then washed twice by centrifugation at $400 \mathrm{~g}$ for 10 minutes at room temperature, with removal of supernatant and resuspension in TCM containing 10\% FCS between washes. After washing, the PBMC were resuspended in TCM containing 5\% FCS and the cell density was adjusted to $1 \times 10^{6}$ lymphocytes $/ \mathrm{mL}$. 
Paternal PBMC (stimulator cells) were thawed by the same procedure as for the maternal PBMC. The stimulator cells were treated with $4 \%$ paraformaldehyde (PFA, Merck Eurolab AB, Stockholm, Sweden) in phosphate-buffered saline (PBS; EC Diagnostics AB, Uppsala, Sweden) for 10 minutes at room temperature to inhibit cytokine secretion. The cells were then washed in PBS and centrifuged at $800 \mathrm{~g}$ for 10 minutes at room temperature. Washing was repeated twice, after which the cells were resuspended in TCM containing 5\% FCS and the cell density was adjusted to $1 \times 10^{6} \mathrm{PBMC} / \mathrm{mL}$.

\subsection{Mixed leukocyte culture (MLC)}

The alloreactivity and cytokine secretion from responder cells, i. e. maternal lymphocytes, was determined by using a one-way MLC as previously described (Ekerfelt et al., 1997).

Sterile nitrocellulose-bottomed 96-well microtiter plates (Millipore AB, Sundbyberg, Sweden) were incubated over night at $+4^{\circ} \mathrm{C}$ with $100 \mu \mathrm{L}$ of mouse anti-human IFN- $\gamma$ 1-D1K monoclonal antibody (mAb) or mouse anti-human IL-4-I mAb (both antibodies from MabTech

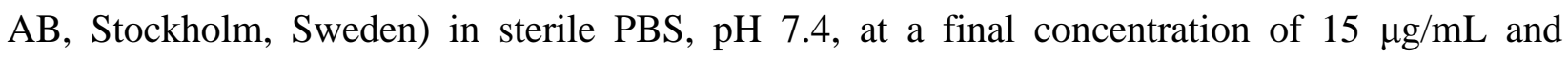
subsequently frozen in $-20^{\circ} \mathrm{C}$. Before use, the plates were thawed by incubation at $+37^{\circ} \mathrm{C}$ for a maximum of 30 minutes, emptied by vacuum suction and washed eight times with $100 \mu \mathrm{L} /$ well of PBS. Unspecific binding sites on the nitrocellulose membrane were blocked by incubating the plates with $100 \mu \mathrm{L} /$ well of $\mathrm{TCM}$ containing $5 \% \mathrm{FCS}$ at $37^{\circ} \mathrm{C}$ for at least 30 minutes.

After emptying of the plates, $100 \mu \mathrm{L}$ of responder cell suspension containing $1 \times 10^{5}$ cells and $100 \mu \mathrm{L}$ of cell suspension containing the same number of PFA-treated stimulator cells expressing paternal antigens, was added to the wells in triplicates for detection of responder cell secretion of IFN- $\gamma$ and IL-4. Spontaneous cytokine secretion was determined by mixing responder cells with TCM containing 5\% FCS. Maternal lymphocytes stimulated with 
phytohaemagglutinine (PHA; Sigma Aldrich, Stockholm, Sweden) were used as a positive control (Figure 2), and negative controls included PFA-treated stimulator cells stimulated with PHA and wells containing TCM only. The cells were cultured at $37^{\circ} \mathrm{C}$ with $5 \% \mathrm{CO}_{2}$ for $24 \mathrm{~h}$, which was previously found to be the optimum time of incubation (Ekerfelt et al., 1997).

\subsection{Detection of cytokine secreting cells}

For the enumeration of cytokine secreting cells, enzyme-linked immuno-sorbent spotforming assay (ELISpot) was performed. After incubation, the plates were emptied and washed twice with PBS and twice with PBS containing 0.05\% Tween 20 (PBS-T; EC Diagnostics). 100 $\mu \mathrm{L} /$ well of biotinylated anti-human IFN- $\gamma$ 7-B6-1 mAb and biotinylated anti-human IL-4-II mAb (both antibodies from MabTech AB, Stockholm, Sweden) diluted to $1 \mu \mathrm{g} / \mathrm{mL}$ in PBS-T, was added, followed by a two hour incubation in a moist chamber at room temperature. The plates were then washed four times with PBS-T and incubated for another hour with $100 \mu \mathrm{L} /$ well of streptavidin conjugated with alkaline phosphatase (MabTech AB, Stockholm, Sweden) diluted 1:1000 in PBS-T. After washing four times with PBS, spots were developed by a 15 minute incubation with $100 \mu \mathrm{L} /$ well of AP conjugate substrate kit (BioRad, Solna, Sweden). Subsequently, the plates were thoroughly rinsed with deionized water and dried over night in darkness, at room temperature. The spots were counted using the ELISpot reader system Transtec 1300 (Autoimmune Diagnostica GmbH, Strasburg, Germany) and the median value of the triplicates was calculated.

\subsection{Statistics}

All data were analyzed with SPSS (SPSS Inc., Chicago, Illinois, USA). Statistical analysis involved three-way analysis of variance with time and diagnosis as fixed factors and subject as 
random factor nested within diagnosis. Pair-wise comparisons between data from the same individuals at different times during and after pregnancy were made using the Bonferroni correction for the adjustment of multiple comparisons.

Paired samples t-test was used to compare the spontaneous secretion with the paternal PBMC induced secretion among all pregnant women, regardless of diagnosis.

Comparison of IFN- $\gamma / \mathrm{IL}-4$ ratios, as a measure of Th1/Th2 balance, was done by t-test. The criterion for significance was $p<0.05$.

\section{RESULTS}

Three-way analysis of variance showed no difference in the numbers of spontaneously or paternal antigen induced IFN- $\gamma$ or IL-4-secreting cells between allergic and non-allergic pregnant women on any occasion (Figure 3). Also, no differences in IFN- $\gamma / \mathrm{IL}-4$ ratios between allergic and non-allergic pregnant women were found on any occasion. However, when analyzing all women, regardless of allergy diagnosis, both the numbers of spontaneously and paternal antigen induced IFN- $\gamma$ and IL-4 secreting cells changed during the course of pregnancy (Figure 4). Thus, the number of cells spontaneously secreting IFN- $\gamma$ and IL-4 was higher in gestational weeks 25 and 35 compared with the non-pregnant state (1 year post partum). In addition, the number of IL4 secreting cells was increased in week 25 compared with the sample taken 8-12 weeks pp. (Figure 4). Also, the numbers of IFN- $\gamma$ secreting cells induced by paternal antigen were increased in weeks 35 and 39, and numbers of IL-4 secreting cells were increased in gestational weeks 25, 35 and 39, compared both with the sample taken 8-12 weeks pp. and with the non-pregnant state (1 year pp., Figure 4). In addition, the number of IFN- $\gamma$ secreting cells was also increased in week 25 compared with 8-12 weeks pp, and the numbers of IL-4-secreting cells were increased in week 
15-16 and week 41 compared with 8-12 weeks pp, but lower in gestation week 10-12 compared with week 35 (Figure 4). The numbers of paternal antigen induced cytokine secreting cells were higher than the numbers of spontaneously secreting cells. For IFN- $\gamma$, this held true in gestation weeks 10-12, 15-16, 25, 35 and 39 (Figure 5a), and for IL-4 on all occasions except at delivery (Figure 5b).

\section{DISCUSSION}

This study aimed to test the hypothesis that allergic women have a more pronounced $\mathrm{Th} 2$ deviation throughout pregnancy than non-allergic women. However, statistical analysis of variance revealed similar numbers of spontaneously and paternal antigen-induced IFN- $\gamma$ or IL-4 secreting cells in allergic and non-allergic pregnant women.

The longitudinal design of the present study, combined with several time points of sampling, allows a detailed analysis of the dynamics of the systemic immune responses during and after pregnancy. An important finding was the increase in the numbers of both spontaneously and paternal antigen induced IFN- $\gamma$ - and IL-4-secreting cells during pregnancy, when compared with the non-pregnant state (1 year post partum). Although allergen-specific cells may be already activated and differentiated towards Th2 cells in allergic pregnant women, this would not affect the results since stimulation with paternal antigens will only stimulate cells specific for paternal antigens and not allergen-specific T-cells. Moreover, the data on spontaneously IFN- $\gamma$ - and IL-4secreting cells, in allergic as well as non-allergic women, agree with our previous published data that both the numbers of ex-vivo IFN- $\gamma$ - and IL-4-secreting cells are increased during pregnancy (Matthiesen et al., 1998; Matthiesen et al., 2003), speaking against an erroneous result due to already activated cells in allergic pregnant women. 
Previous studies have shown that the effects of IL-4 predominate over the effects of IFN- $\gamma$ (Sadick et al., 1990; Morris et al., 1993; Racke et al., 1994). Sadick et al. (1990) found a profound effect of neutralization of IL-4 on the course of infection by Leishmania major in mice. Eighty-five percent of the mice were cured, and cure was independent of IFN- $\gamma$. Morris et al. (1993) proposed that IFN- $\gamma$ is produced by all mice during a Leishmania major infection, and that it is the dominant effect of IL-4 and/or other lymphokines that determines the severity of the disease. In the study by Racke et al. (1994), T cells from IL-4 treated mice with experimental allergic encephalomyelitis (EAE) produced amounts of IFN- $\gamma$ equivalent to or greater than those produced by $\mathrm{T}$ cells from PBS-treated controls. Administration of IL-4 resulted in a dramatic reduction of clinical disease.

The results of these previous studies suggests that the increase in both IFN- $\gamma$ and IL-4 secreting cells in the present study may be interpreted as a Th2-situation, both for spontaneous and paternal antigen-induced responses.

Considering the dynamics during pregnancy, it is clear that, at the systemic level, the major changes occur in the second and third trimesters. The increase in spontaneously cytokine secreting cells shows maximum peaks in weeks 25-35 and then a decline, whereas the increase of paternally induced cytokine secretion is maintained from week 25 throughout pregnancy. Post partum, there were no differences between week 8-12 and one year, indicating that the major restitution in systemic immunity is restored in week 8-12.

Although the present study on peripheral blood mononuclear cells does not support the hypothesis of a more pronounced Th2-deviation in allergic pregnant women compared with nonallergic pregnant women, which may favor pregnancy, the hypothesis can not be rejected. Firstly, we studied the number of cytokine secreting cells in blood, measured by ELISpot, which may not 
reflect the concentrations of cytokines secreted. Measuring the cytokine levels i peripheral blood may reveal different amounts of IFN- $\gamma$ and IL-4 secreted by allergic and non-allergic women during pregnancy. The rationale for using ELISpot was that detection of IL-4 requires a highly sensitive technique, and we have previously shown ELISpot to be the most sensitive method for detection of IL-4, indeed the only technique sensitive enough for detection of spontaneous IL-4 secretion (Ekerfelt et al., 2002a). Secondly, this study was performed on frozen cells, and since cryopreservation has been reported to decrease the secretion of IL-4 (Ekerfelt et al., 1997; Kvarnstrom et al., 2004), larger numbers of IL-4 secreting cells may have been detected if fresh cells had been analyzed. Thirdly, the systemic cytokine secretion measured in the current study may not necessarily reflect local cytokine patterns. Indeed, we have previously shown that the cytokine secretion in peripheral blood does not reflect the local cytokine milieu in the decidua during the first trimester of normal pregnancy (Ekerfelt et al., 2002b). Thus, the local cytokine responses in allergic and non-allergic pregnant women may still differ. Also, we have recently observed an enhanced Th2 deviation, reflected by increased total IgE levels during pregnancy in allergic women, but not in non-allergic women (Sandberg et al., submitted manuscript).

The findings of previous studies on atopy and parity are contradictory. These discrepancies may be due to the different methods used to diagnose atopy. Nilsson and colleagues (Nilsson et al., 1997) used questionnaires for this purpose, a procedure that may involve a problem of bias. Sunyer and colleagues based their diagnosis on IgE measurements (Sunyer et al., 2005) or skin prick tests performed during pregnancy (Sunyer et al., 2001). The possibility that the clinical history of atopy and sensitization are different phenomena may also contribute to the contradictory results of earlier studies. We thus used more strict criteria, based on the presence or absence of both symptoms and sensitization. Seasonal exposure to $e g$ pollen influences $\operatorname{IgE}$ 
antibody levels in allergic individuals. However, this phenomenon is not considered to be a confounding factor in our study. We have recently measured total and specific IgE in the allergic and non-allergic pregnant women included in the present study, and no changes in specific IgE antibody levels were detected over the analyzed time (Sandberg et al., submitted manuscript).

No statistically significant interaction between time and group was seen, meaning that the change in cytokine secretion over time in allergic women did not differ significantly from the change over time in non-allergic women. The use of a subject factor nested within group, demands, besides the usual assumption of normal distributed residuals, that the subjects are normally distributed within both groups. We checked the random components and found no major deviations from normal distribution in neither residuals nor subject effects.

In conclusion, the present study does not support the hypothesis of a more pronounced Th2deviation in allergic women during pregnancy. The observed increase of both IFN- $\gamma$ and IL-4 secreting cells during the second and third trimesters of normal pregnancy is in agreement with previous studies, and may be interpreted as a Th2-situation, since the effects of IL-4 predominate over the effects of IFN- $\gamma$.

\section{ACKNOWLEDGEMENTS}

We would like to thank Olle Eriksson, Department of Mathematics, Division of Statistics, Linköping University, Sweden, for invaluable help with statistical methods and analysis, the couples that participated in the study, the staff at the maternity health care clinic, and research nurse Lena Lindell. 


\section{REFERENCES}

Aris, A., Lambert, F., Bessette, P. Moutquin, J.M., 2008. Maternal circulating interferon-gamma and interleukin- 6 as biomarkers of Th1/Th2 immune status throughout pregnancy. $\mathrm{J}$ Obstet Gynaecol Res 34, 7-11.

Boyum, A., 1968. Isolation of mononuclear cells and granulocytes from human blood. Scand J Clin Lab Invest Suppl 97, 77-89.

Del Prete, G.F., De Carli, M., D'Elios, M.M., Maestrelli, P., Ricci, M., Fabbri, L., Romagnani, S., 1993. Allergen exposure induces the activation of allergen-specific Th2 cells in the airway mucosa of patients with allergic respiratory disorders. Eur J Immunol 23, 14451449.

Ekerfelt, C., Ernerudh, J., Jenmalm, M.C., 2002a. Detection of spontaneous and antigen-induced human interleukin-4 responses in vitro: comparison of ELISPOT, a novel ELISA and real-time RT-PCR. J Immunol Methods 260, 55-67.

Ekerfelt, C., Lidstrom, C., Matthiesen, L., Berg, G., Sharma, S., Ernerudh, J., 2002b. Spontaneous secretion of interleukin-4, interleukin-10 and interferon-gamma by first trimester decidual mononuclear cells. Am J Reprod Immunol 47, 159-166.

Ekerfelt, C., Matthiesen, L., Berg, G., Ernerudh, J., 1997. Paternal leukocytes selectively increase secretion of IL-4 in peripheral blood during normal pregnancies: demonstrated by a novel one-way MLC measuring cytokine secretion. Am J Reprod Immunol 38, 320-326.

Ishizaka, K., Ishizaka, T., 1971. Mechanisms of reaginic hypersensitivity: a review. Clinical Allergy 1, 9-24.

Jenmalm, M.C., van Snick, J., Cormont, F., Salman, B., 2001. Allergen-induced Th1 and Th2 cytokine secretion in relation to specific allergen sensitization and atopic symptoms in children. Clin Exp Allergy 31,1528-1535.

Karmaus, W., Eneli, I., 2003. Maternal atopy and the number of offspring: is there an association? Pediatr Allergy Immunol 14, 470-474.

Kwak-Kim, J.Y., Chung-Bang, H.S., Ng, S.C., Ntrivalas, E.I., Mangubat, C.P., Beaman, K.D., Beer, A.E., Gilman-Sachs, A., 2003. Increased T helper 1 cytokine responses by circulating $\mathrm{T}$ cells are present in women with recurrent pregnancy losses and in infertile women with multiple implantation failures after IVF. Hum Reprod 18, 767-773.

Kvarnstrom, M., Jenmalm, M.C., Ekerfelt, C., 2004. Effect of cryopreservation on expression of Th1 and Th2 cytokines in blood mononuclear cells from patients with different cytokine profiles, analysed with three common assays: an overall decrease of interleukin-4. Cryobiology 49, 157-168.

Lin, H., Mosmann, T.R., Guilbert, L., Tuntipopipat, S., Wegmann, T.G., 1993. Synthesis of T helper 2-type cytokines at the maternal-fetal interface. J Immunol 151, 4562-4573.

Makhseed, M., Raghupathy, R., Azizieh, F., Farhat, R., Hassan, N., Bandar, A., 2000. Circulating cytokines and CD30 in normal human pregnancy and recurrent spontaneous abortions. Hum Reprod 15, 2011-2017.

Makhseed, M., Raghupathy, R., Azizieh, F., Omu, A., Al-Shamali, E., Ashkanani, L., 2001. Th1 and Th2 cytokine profiles in recurrent aborters with successful pregnancy and with subsequent abortions. Hum Reprod 16, 2219-2226.

Marzi, M., Vigano, A., Trabattoni, D., Villa, M.L., Salvaggio, A., Clerici, E., Clerici, M., 1996. Characterization of type 1 and type 2 cytokine production profile in physiologic and pathologic human pregnancy. Clin Exp Immunol 106, 127-133. 
Matthiesen, L., Ekerfelt, C., Berg, G., Ernerudh, J., 1998. Increased numbers of circulating interferon-gamma- and interleukin-4-secreting cells during normal pregnancy. Am J Reprod Immunol 39, 362-367.

Matthiesen, L., Khademi, M., Ekerfelt, C., Berg, G., Sharma, S., Olsson, T., Ernerudh, J., 2003. In-situ detection of both inflammatory and anti-inflammatory cytokines in resting peripheral blood mononuclear cells during pregnancy. J Reprod Immunol 58, 49-59.

Morris, L., Troutt, A.B., McLeod, K.S., Kelso, A., Handman, E., Aebischer, T., 1993. Interleukin-4 but not gamma interferon production correlates with the severity of murine cutaneous leishmaniasis. Infect Immun 61, 3459-3465.

Nilsson, L., Kjellman, N.I., Lofman, O., Bjorksten, B., 1997. Parity among atopic and non-atopic mothers. Pediatr Allergy Immunol 8, 134-136.

Parronchi, P., Macchia D., Piccinni, M.P., Biswas, P., Simonelli, C., Maggi, E., Ricci, M., Ansari, A.A., Romagnani, S., 1991. Allergen- and bacterial antigen-specific T-cell clones established from atopic donors show a different profile of cytokine production. Proc Natl Acad Sci USA 88, 4538-4542.

Parronchi, P., De Carli, M., Manetti, R., Simonelli, C., Piccinni, M.P., Macchia, D., Maggi, E., Del Prete, G., Ricci, M., Romagnani, S., 1992. Aberrant interleukin (IL)-4 and IL-5 production in vitro by CD4+ helper T cells from atopic subjects. Eur J Immunol 22, 16151620.

Pene, J., Rousset, F., Briere, F., Chretien, I., Paliard, X., Banchereau, J., Spits, H., De Vries, J.E., 1988. IgE production by normal human B cells induced by alloreactive $\mathrm{T}$ cell clones is mediated by IL-4 and suppressed by IFN-gamma. J Immunol 141, 1218-1224.

Piccinni, M.P., Beloni, L., Livi, C., Maggi, E., Scarselli, G., Romagnani, S., 1998. Defective production of both leukemia inhibitory factor and type $2 \mathrm{~T}$-helper cytokines by decidual $\mathrm{T}$ cells in unexplained recurrent abortions. Nat Med 4, 1020-1024.

Racke, M.K., Bonomo, A., Scott, D.E., Cannella, B., Levine, A., Raine, C.S., Shevach, E.M., Rocken, M., 1994. Cytokine-induced immune deviation as a therapy for inflammatory autoimmune disease. J Exp Med 180, 1961-1966.

Raghupathy, R., Makhseed, M., Azizieh, F., Hassan, N., Al-Azemi, M., Al-Shamali, E., 1999. Maternal Th1- and Th2-type reactivity to placental antigens in normal human pregnancy and unexplained recurrent spontaneous abortions. Cell Immunol 196, 122-130.

Raghupathy, R., Makhseed, M., Azizieh, F., Omu, A., Gupta, M., Farhat, R., 2000. Cytokine production by maternal lymphocytes during normal human pregnancy and in unexplained recurrent spontaneous abortion. Hum Reprod 15, 713-718.

Romagnani, S., Del Prete, G., Maggi, E., Parronchi, P., Tiri, A., Macchia, D., Giudizi, M.G., Almerigogna, F., Ricci, M., 1989. Role of interleukins in induction and regulation of human IgE synthesis. Clin Immunol Immunopathol 50, S13-23.

Sadick, M.D., Heinzel, F.P., Holaday, B.J., Pu, R.T., Dawkins, R.S., Locksley, R.M., 1990. Cure of murine leishmaniasis with anti-interleukin 4 monoclonal antibody. Evidence for a $\mathrm{T}$ cell-dependent, interferon gamma-independent mechanism. J Exp Med 171, 115-127.

Saito, S., Umekage, H., Sakamoto, Y., Sakai, M., Tanabe, K., Sasaki, Y., Morikawa, H., 1999. Increased T-helper-1-type immunity and decreased T-helper-2-type immunity in patients with preeclampsia. Am J Reprod Immunol 41, 297-306.

Savilahti, E., Siltanen, M., Pekkanen, J., Kajosaari, M., 2004. Mothers of very low birth weight infants have less atopy than mothers of full-term infants. Clin Exp Allergy 34, 1851-1854. 
Shimojo, N., Kohno, Y., Katsuki, T., Hoshioka, A., Honma, K., Saito, K., Niimi, H., 1996. Diminished interferon-gamma (IFN- $\gamma$ ) production by bacterial antigen-specific T cells in atopic patients. Clin Exp Immunol 106, 62-66.

Somoskovi, A., Bartfai, Z., Tamasi, L., Kocsis, J., Puho, E., Czeizal, A.E., 2007. Populationbased case-control study of allergic rhinitis during pregnancy for birth outcomes. Eur J Obstet Gynecol Reprod Biol 131, 21-27.

Sunyer, J., Anto, J.M., Harris, J., Torrent, M., Vall, O., Cullinan, P., Newman-Taylor, A., 2001. Maternal atopy and parity. Clin Exp Allergy 31, 1352-1355.

Sunyer, J., Anto, J.M., Plana, E., Janson, C., Jarvis, D., Kony, S., Omenaas, E.R., Svanes, C., Wjst, M., Leynaert, B., 2005. Maternal atopy and changes in parity. Clin Exp Allergy 35, $1028-1032$

Wegmann, T.G., Lin, H., Guilbert, L., Mosmann, T.R., 1993. Bidirectional cytokine interactions in the maternal-fetal relationship: is successful pregnancy a TH2 phenomenon? Immunol Today 14, 353-356. 


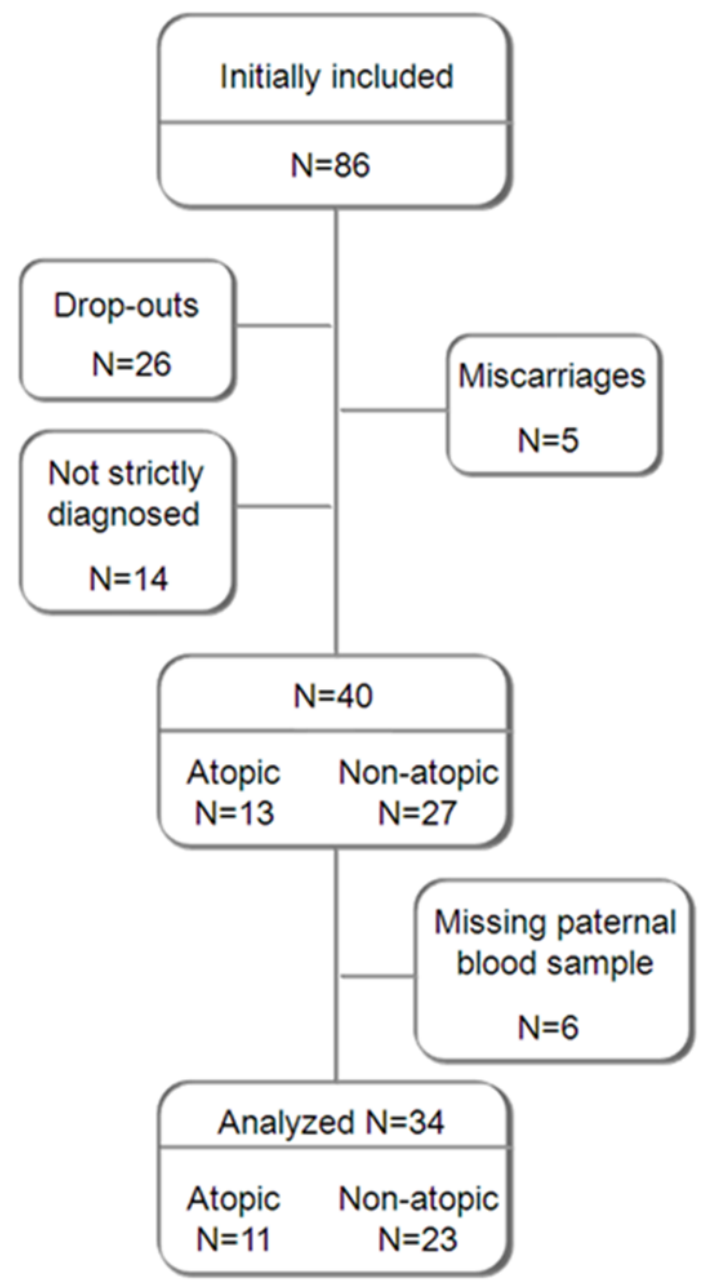

Figure 1. Flow chart of subjects included in the present study. Among the 54 women who had a normal pregnancy and completed the sampling procedures, 11 fulfilled the strict criteria for allergy and 23 were strictly non-allergic. Drop-outs = women who chose not to participate in the study. Not strictly diagnosed $=$ women with either a positive Phadiatop test and no clinical symtoms, or a negative Phadiatop test and typical clinical symtoms. 

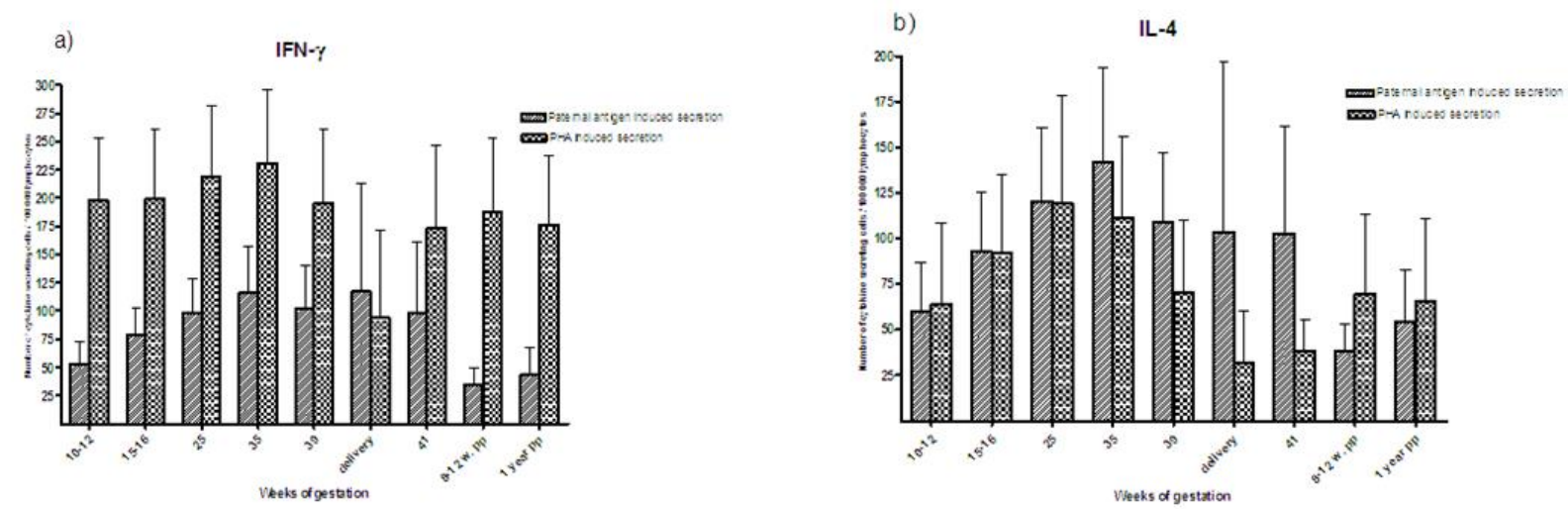

Figure 2. The figure shows the capacity of maternal cells to respond to PHA and paternal antigens. The bars represent the number of IFN- $\gamma$ (a) and IL-4 (b) secreting cells in pregnant women. 

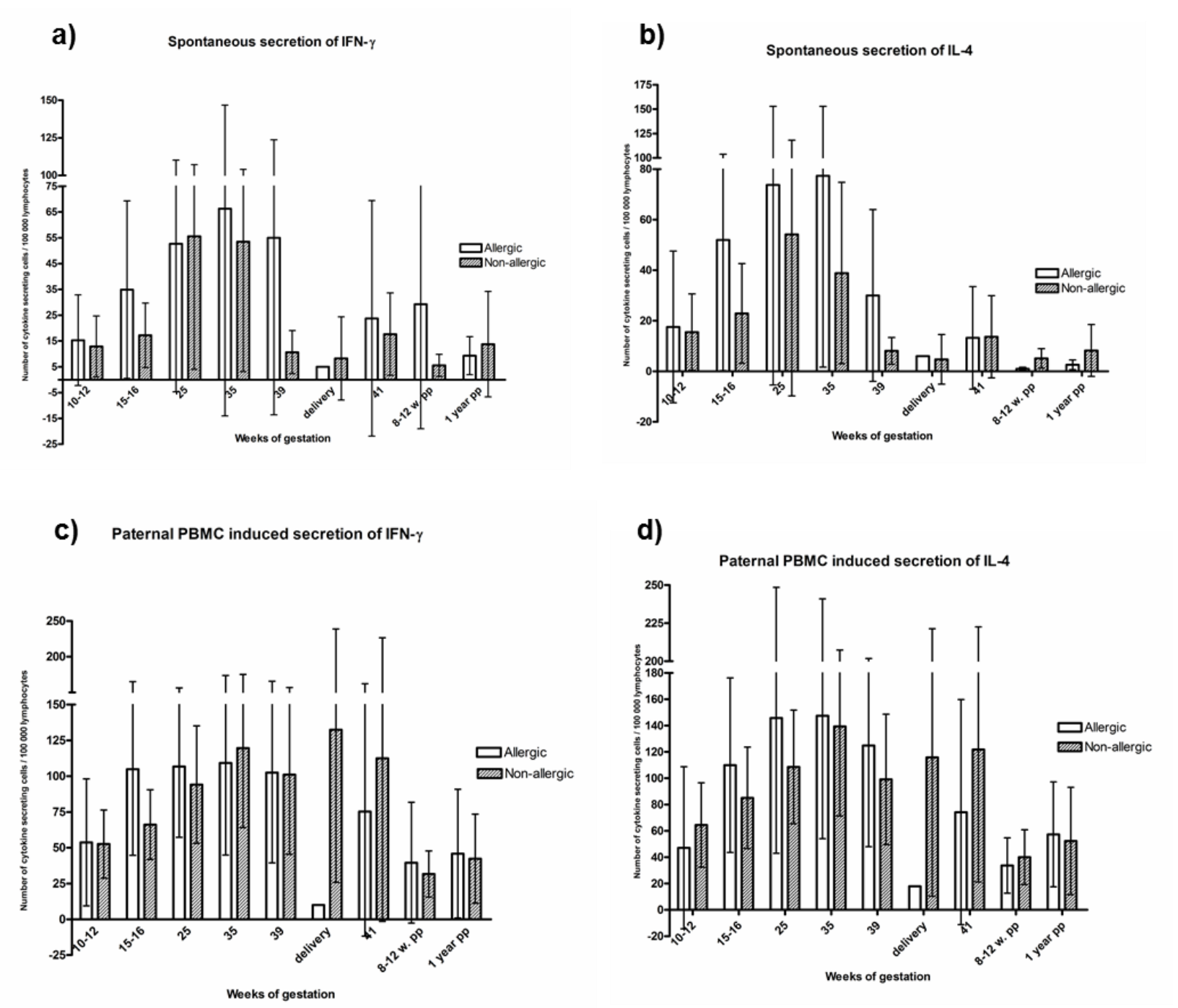

Figure 3. The number of spontaneously (a, b) and paternal antigen induced (c, d) IFN- $\gamma$ and IL-4 secreting cells in allergic and non-allergic pregnant women. Mean values and 95\% confidence intervals are shown. 
Spontaneous secretion of IFN- $\gamma$
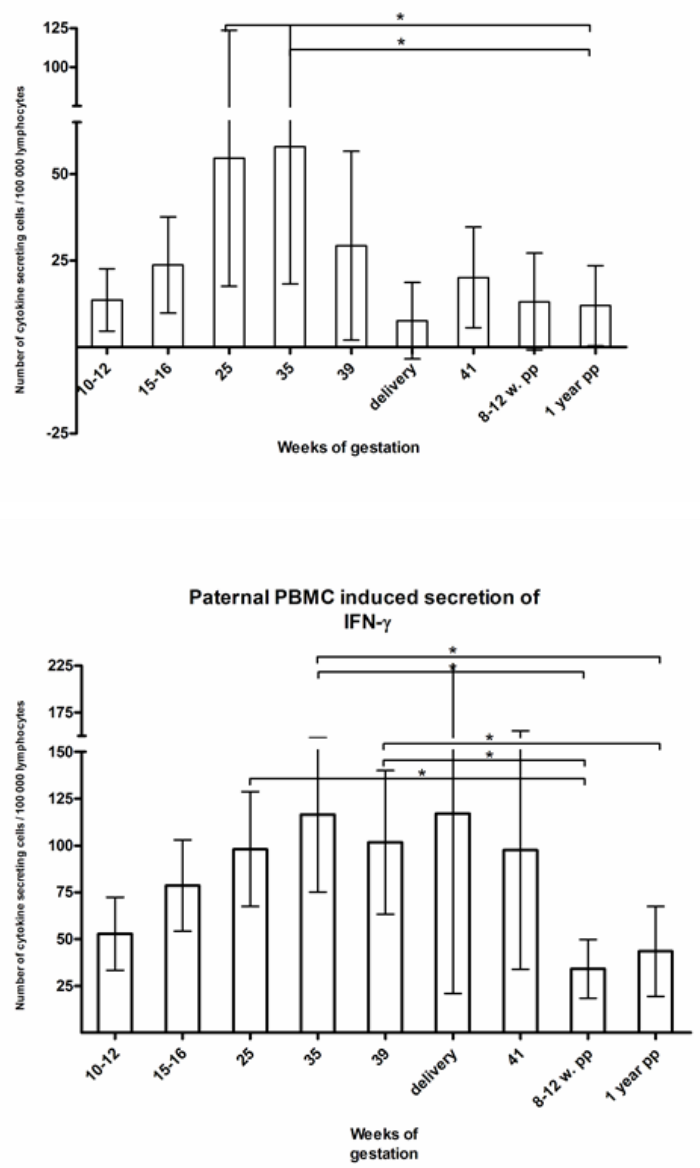

Spontaneous secretion of IL-4

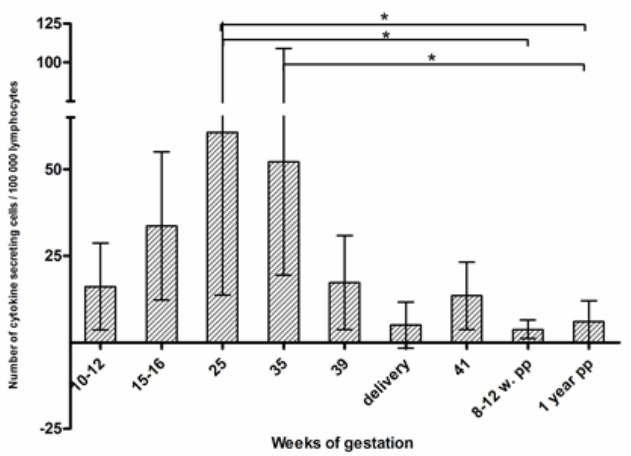

Paternal PBMC induced secretion of

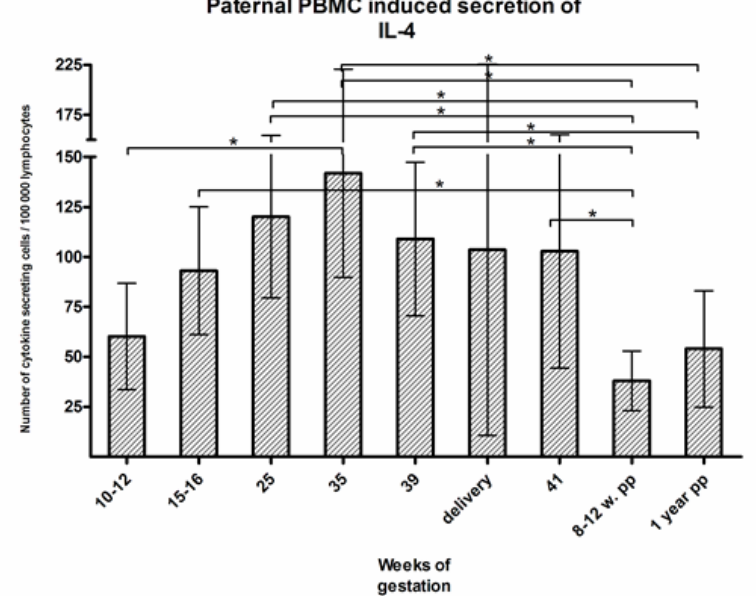

Figure 4. The number of spontaneously IFN- $\gamma$ (a) and IL-4 (b) secreting mononuclear cells and paternal antigen induced IFN- $\gamma$ (c) and IL-4 (d) secreting mononuclear cells in blood from women with normal pregnancy, regardless of allergy diagnosis. Mean values and 95\% confidence intervals are shown. $\mathrm{p}$ values $<0.05$ from statistical three way analysis of variance are indicated $(*)$. 

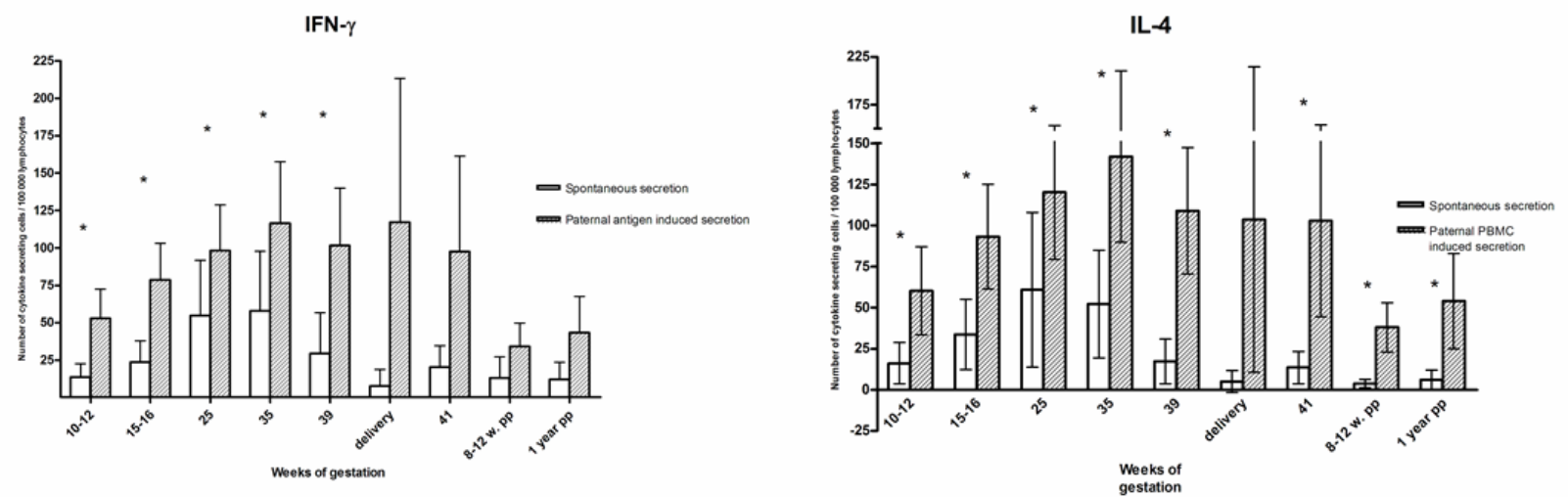

Figure 5. Comparison of the numbers of spontaneously and paternal antigen induced IFN- $\gamma$ (a) and IL-4 (b) secreting mononuclear cells in blood from women with normal pregnancy, regardless of allergy diagnosis. Mean values and 95\% confidence intervals are shown. $\mathrm{p}$ values $<0.05$ from paired samples $\mathrm{T}$ test are indicated $(*)$. 